1 Prentice, A. J. R., and ter Haar, D., Nature, 222, 964 (1969).

2 Prentice, A. J. R., and ter Haar, I)., Mon. Not. Roy. Astron. Soc., 146, 423 (1969).

s Davies, J. G., Large, M. I., and Pickwick, A. C., Nature, 227, 1123 (1970).

- Davies, J. G., and Large, M. Y., Mon. Not. Roy. Astron. Soc., 149, 301 (1970),

${ }^{5}$ Smith, L. F., Mon. Not. Roy. Astron. Soc., 141, 317 (1968).

6 Tsytovich, V. N., Buckee, J. W., and ter Haar, D., Phys. Lett. (in the press).

${ }^{7}$ Hunt, G. C., Nature, 224, 1005 (1969).

${ }^{8}$ Reichley, P., Downs, G., and Morris, D., Ap. J.,159, L35 (1970).

\section{Plate Tectonics of the Red Sea and East Africa}

I would like to comment on some of the assumptions and results of a recent letter by McKenzie et al. ${ }^{1}$. They reconstruct the pre-movement position of Arabia and Africa by fitting the two coast lines of the Red Sea, assuming that the entire space between the coasts is occupied by newly formed oceanic crust. This assumption ignores the existence of the Danakil horst, which consists of continental crust (Pre-Cambrian, Jurassic) and which is some $80 \mathrm{~km}$ wide, in between theso two coast lines in the southern Red Sea depression. It seems impossible to close the gap of the Red Sea without leaving the space required for this continental block.

This reconstruction on a pole of rotation at $36.5^{\circ} \mathrm{N}$, $18^{\circ}$, off western Greece leads (ref. 1, Fig. 4) to a considerable extensional component along the Dead Sea rift. This does not correspond to the nature of the movement along this fault line, where the strike slip movement is dominant, with minor extension alternating along it with large shortening in Lebanon ${ }^{2}$. This reconstruction leads finally to a crustal separation of $60-90 \mathrm{~km}$ across the Gulf of Suez. This is difficult to reconcile with the fact that the total width of the Gulf of Suez depression does not exceed $50 \mathrm{~km}$ in the north and $65 \mathrm{~km}$ in the south. Furthermore, there are blocks of continental material within the depression, that of Gebel Kabiliat in the west and of Gebel Zeit in the east. The extension across the Gulf of Suez cannot therefore exceed $25-30 \mathrm{~km}$, according to the assumption of McKenzie et al. that the crust has thinned by half beneath the Gulf. This leaves a 40-60 km excess discrepancy with their results. Thus the two coast lines of the Red Sea could not be said to be matching. Instead, they may reflect the marginal faults of a rift which formed at the early stages of the opening of the Red Sea. Judging from the East African rifts, the marginal faults are usually nearly parallel, and the width of such a rift is about $60 \mathrm{~km}$.

The reconstruction should therefore be carried out not by fitting the two coast lines, but by fitting two lines which are about $20-30 \mathrm{~km}$ seawards from each coast. This might be the place where the $2,000 \mathrm{~m}$ depth contour (which is the most reliable outline of the continents ${ }^{3}$ ) could be expected in such a fresh crustal separation, were it not concealed by the thick sedimentary cover.

It is true that such a suggestion leaves a wide margin of inaccuracy if a precise reconstruction of the positions of the African and Arabian plates is attempted. The pole of rotation found manually, according to the assumption that there was originally a rift $60 \mathrm{~km}$ wide along the Red Sea, occurs at about $32^{\circ} \mathrm{N}, 22^{\circ} \mathrm{E}$, north-west of Egypt.

Department of Geology,

Raphael Freund

The Hebrew University,

Jerusalem.

Received June 8, 1970.

1 McKenzie, P. D., Davies, D., and Molnar, P., Nature, 226, 243 (1970).

2 Freund, R., Geol. Mag., 102, 189 (1965).

3 Bullard, E. C.. Everett, J. E., and Smith, A. G., Phil. Trans. Roy. Soc., A, 258, $41(1965)$.

\section{Magnesium, Organic Matter and Soil Structure}

SURFACE soils with good structure consist of aggregates that do not disintegrate on sudden wetting with water to form a crust when re-dried. Crusting is most severe when disintegration proceeds down to the level of clay sized particles. The beneficial effect of soil organic matter in reducing the break-up of initially dry soil aggregates when wetted with water is well known. Equally well known is the deleterious effect of exchangeable sodium in causing spontaneous dispersion of clay from aggregates if the external electrolyte concentration is reduced when the soil is wetted. Spontaneous dispersion does not occur if the exchange complex of a soil is effectively saturated with $\mathrm{Ca}$ ions or if sufficient organic matter is present ${ }^{1}$. If external work is performed on such soils when they ar. wet, however, then spontaneous dispersion may occur ${ }^{2}$. Thus a surface soil can apparently have a good structure as measured by the slaking (break-up) of dry aggregates in water and yet after shearing, as in tillage, it may still crust badly ${ }^{3}$.

The present work was undertaken to determine, first, whether there is a difference in the ease of dispersion of a sheared surface soil when saturated with $\mathrm{Mg}$ rather than $\mathrm{Ca}$ ions; second, to show directly, by the addition of organic compounds to the oxidized clay fraction extracted from the surface soil and the corresponding untreated subsoil, that dispersion can be enhanced by organic matter.

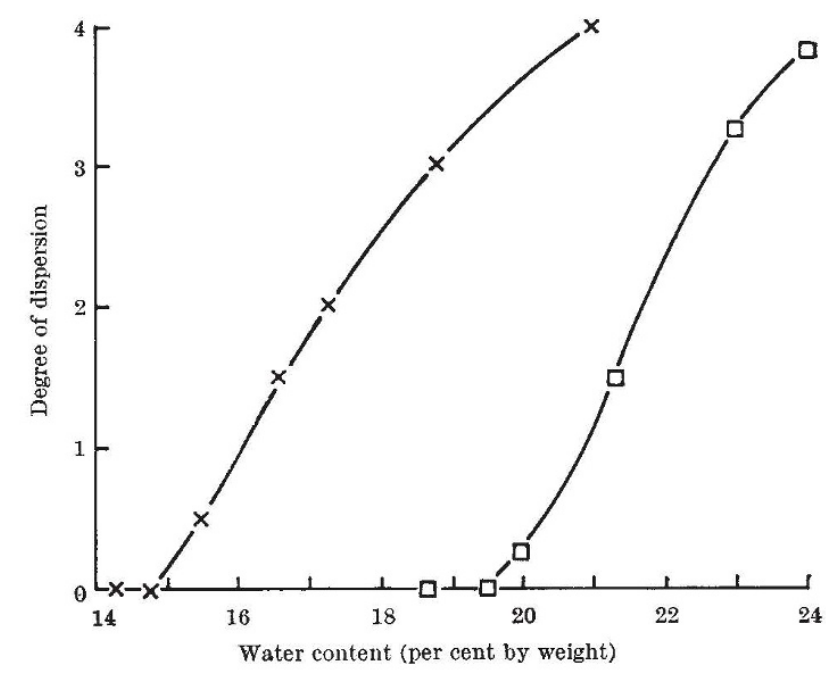

Fig. 1. The visual dispersion in water of surface aggregates of a red earth remoulded at various water contents. $\times$, Washed $\mathrm{MgCl}_{2} ; \square$, washed $\mathrm{CaCl}$.

The degree of dispersion in water of remoulded surface aggregates of a kaolinitic red $\operatorname{earth}^{3}$ (C content $\mathrm{I} \cdot 3$ per cent) washed with either $\mathrm{CaCl}_{2}$ or $\mathrm{MgCl}_{2}$ is shown in Fig. 1 as a function of the initial water content of the aggregates. Dispersion was assessed visually using the scale 0 to 4 , where 4 means apparently complete dispersion into primary particles. This simple technique is adequate for detecting the first appearance of dispersed clay. The Mg-washed soil showed signs of dispersion when remoulded at a water content of 15 per cent by weight whereas the $\mathrm{Ca}$ soil started to disperse at 20 per cent. The difference is significant because the field capacity of this soil is about 20 per cent by weight.

Various commonly used organic dispersants such as $\mathrm{Na}$-carboxymethyl cellulose and $\mathrm{Na}$-citrate were added to the peroxidized clay fraction $(<2 \mu)$ of the surface soil and the untreated subsoil. After washing the mixtures 